\title{
DIÁLOGOS AUTOBIOGRÁFICOS: POSSIBILIDADES FORMATIVAS DO CONHECIMENTO DE SI NO INÍCIO DA DOCÊNCIA SUPERIOR
}

\author{
AUTOBIOGRAPHICAL DIALOGUES: FORMATIVE POSSIBILITIES \\ SELF-KNOWLEDGE IT THE BEGINNING OF TEACHING IN \\ HIGHER EDUCATION
}

\section{CONVERSACIONES AUTOBIOGRÁFICAS: POSIBILIDADES FORMATIVAS DEL CONOCIMIENTO DE SI EN EL PRINCIPIO DE LA DOCENCIA SUPERIOR}

Renata Cristina da Cunha*

Professora no Instituto Federal de Educação, Ciência e Tecnologia do Piauí e Ensino Superior no curso de Letras-Inglês da Universidade Estadual do Piauí.

\section{Rosa Maria Moraes Anunciato de Oliveira**}

Coordenadora do Programa de Pós-graduação em Educação na Universidade Federal de São Carlos

Resumo: O objetivo deste artigo é analisar as reflexões potencializadas pela produção e discussão de narrativas orais e escritas. Essas reflexões revelaram as experiências formadoras vivenciadas pelos professores universitários ao longo de sua trajetória de vida e durante a realização do estudo de natureza autobiográfica, fundamentado em Delory-Momberger (2008), Josso (2004) e outros. As narrativas foram produzidas por três professores, graduados em Letras-Inglês, iniciantes na carreira docente na Uespi, em Parnaíba, no ano de 2012. Os diálogos autobiográficos realizados tornaram-se formativos quando os professores assumiram a responsabilidade pela própria formação por meio da escrita e do diálogo, (re)significando e reconfigurando espaços, tempos e experiências vivenciadas, reconhecendo-se como parte integrante e basilar da história.

\footnotetext{
* Doutora em Educação pela Universidade Federal de São Carlos; Mestre em Educação pelo Programa de Pós-Graduação em Educação da Universidade Federal do Piaú́.

** Doutora em Educação pela Universidade Federal de São Carlos; Mestre em Educação pela Universidade Federal de São Carlos.
} 
Palavras-chave: Narrativas autobiográficas. Professores de Língua Inglesa. Aprendizagem da docência. Início da carreira docente.

Abstract: The objective of this paper is to analyze the reflections enhanced by the production and discussion of oral and written narratives. These reflections revealed the formative experiences lived by college professors through their life trajectory and during the execution of this autobiographical research, grounded in Delory-Momberger (2006, 2008, 2009), Josso (2004), among others. The narratives were produced by three English professors who were beginners in the teaching profession at UESPI, in Parnaiba in 2012. The autobiographical dialogues became formative when the professors got the responsibility for their own development writing their narratives and dialoguing with the group, so they could reframe and rebuild spaces, times and lived experiences, recognizing themselves as meaningful part of history.

Keywords: Autobiographical narratives. English professors. Teaching learning process. Beginning in the teaching profession.

Resumen: El objetivo de este artículo es analizar las reflexiones potencializadas por la producción y discusión de narrativas autobiográficas orales y escritas en contexto de investigación- acción-formación docente. Esas reflexiones revelan las experiencias formativas vivenciadas por los maestros universitarios al transcurrir de su trayectoria de vida y en transcurrir a realización del estudio de naturaleza epistémico-biográfica, fundamentando en Delory-Momberger (2008), Josso (2004), y otros. Las narrativas fueron producidas por los tres maestros, graduados en letras-Inglés, principiantes en la carrera docente en la UESPI, en Parnaíba (PI) en el año de 2012. Las conversaciones autobiográficas realizadas se convirtieron en formativas cuando los maestros asumieron la responsabilidad por la propia formación por medio de la escrita y de la conversación. (re)significado y (re)configuración espacios, tiempos y experiencias vividas, reconociéndose como parte integrante y basilar de la historia.

Palabras clave: conversaciones autobiográficas. Maestros de lengua de Inglesa. Aprendizaje de la docencia. Principio de la carrera docente.

\section{CONSIDERAÇÕES INICIAIS: SER INICIANTE NA PROFISSÃO DOCENTE}

Ao longo do processo de formação docente, os primeiros anos de exercício profissional são basilares para a aprendizagem da docência. É o momento da transição de discente para docente. É o início de um caminho, às vezes nada tranquilo, 
para tornar-se professor. As experiências vivenciadas nesse período proporcionam aos principiantes sentimentos e emoções que alternam alegrias e descobertas, tristezas e desapontamentos. Dessas lembranças, emergem não apenas alegrias, encantos e descobertas vivenciadas no período de iniciação à profissão, mas também dúvidas, incertezas e dilemas vivenciados no período, expondo a interface da sobrevivência ao choque da realidade.

Segundo Garcia (1999, p. 39), o professor principiante somente consegue sobreviver ao choque da realidade devido à outra face da moeda, a descoberta, definida como "[...] o entusiasmo inicial, a exaltação por estar, finalmente, em situação de responsabilidade (ter a sua sala de aula, os seus alunos, o seu programa), por se sentir num determinado corpo profissional." A descoberta pode, portanto, superar a sobrevivência, potencializada pelo empenho e motivação com a entrada na carreira. Esses dois sentimentos os estimulam não apenas a fazer um bom trabalho, mas também a aplicar o que aprenderam na formação inicial, tentando inovar e utilizar metodologias atuais de sua disciplina.

Nessa perspectiva, como parte da pesquisa de doutorado (CUNHA, 2014), a questão-norteadora deste trabalho é: O que as reflexões potencializadas pela produção das narrativas autobiográficas orais e escritas revelam sobre as experiências formadoras vivenciadas pelos professores de Letras-Inglês, iniciantes na carreira, ao longo de sua trajetória de vida e durante a realização da pesquisa?

Esta pesquisa autobiográfica de cunho narrativo-interpretativo foi realizada durante o ano de 2012. As narrativas orais e escritas foram produzidas durante os encontros interativos (FREIRE, 1996; MARCUSCHI, 2004) realizados para a socialização das narrativas escritas por três professores de Língua Inglesa, iniciantes na carreira no Ensino Superior na Uespi, campus de Parnaíba (PI), aos quais foram atribuídos os seguintes pseudônimos: Coelho Branco, Rainha Vermelha e Rainha Branca, em virtude da proposta da tese sobre Alice no País do Ensino Superior, apresentados a seguir:

a) O Coelho Branco é natural de Parnaíba - PI, nascido em 1980. Estudou em escolas públicas e privadas da cidade. Concluído o Ensino Médio, passou a trabalhar no comércio. Em 2004, decidiu inscrever-se no vestibular para o curso de Letras-Inglês da Uespi. Durante a graduação foi monitor de quatro disciplinas. Concluída a graduação, fez pós-graduação em Metodologia do Ensino Superior. Em 2011 ingressou no curso de Letras-Inglês da Uespi como professor substituto, 
ministrando disciplinas na área de Literatura, além de orientar alunos em seus trabalhos de conclusão de curso.

b) A Rainha Vermelha nasceu em Parnaíba- PI em 1986. Sempre estudou em escolas particulares. Ao final do $3^{\circ}$ ano foi aprovada no vestibular para Letras-Inglês, iniciando a graduação em 2004. No ano de 2007, um ano antes da conclusão do curso, matriculou-se no curso de especialização em Língua Inglesa. Em 2011 foi aprovada no processo seletivo como professora substituta do curso de Letras-Inglês da Uespi, ministrando disciplinas relacionadas à Língua Inglesa, além de orientar monografias.

c) A Rainha Branca nasceu em Parnaíba, Piauí, em 1985. Estudou em escolas públicas e privadas. Em 2004, um ano após a conclusão do Ensino Médio, foi aprovada no curso de Letras Inglês na Uespi. Ainda no último ano da faculdade, inscreveu-se na especialização em Letras-Inglês. No ano de 2011, ingressou como professora substituta do curso de Letras-Inglês da Uespi, ministrando aulas, orientando alunos em monografias e participando de bancas examinadoras de conclusão de curso e de seleção de professores.

\section{NARRAR-SE: UMA VIA DUPLA PARA A FORMAÇÃO E INVESTIGAÇÃO EM EDUCAÇÃO}

As pesquisas em Educação têm utilizado as narrativas autobiográficas como recurso de investigação-formação para repensar a formação de professores com o objetivo principal de fazer com que estes falem de suas experiências de formação, pois "relativamente à narrativa de vida, presume-se que a narrativa de formação apresente um segmento da vida: aquele durante o qual o indivíduo esteve implicado num projecto de formação." (CHENÉ, 1988, p. 90).

No entanto, de acordo com Josso (2004), as narrativas autobiográficas avançarão apenas se houver questões do narrador, no caso da pesquisa na área de formação de professores questões do professor que possam esclarecer as interfaces do problema investigado, ou seja, o que aconteceu para que esses professores viessem a ter as ideias que têm hoje sobre a profissão docente, espaço de formação e atuação 
profissional. A título de encaminhar a produção das narrativas autobiográficas nessa direção, a pesquisadora sugere os seguintes questionamentos:

Sobre o que eu me apoio para pensar ser aquele ou aquela que penso ser e quero tomar-me? Como me configurei como sou? E como me transformei? Sobre o que me baseio para pensar o que penso? De onde me vem as ideias que acredito minhas? Sobre o que me apoio para fazer o que faço da maneira como faço e/ou pretendo fazer? Com quem e como aprendi meu "saber-fazer" em suas dimensões técnicas, programáticas e relacionais? Sobre o que me apoio para dizer o que digo (a escolha das temáticas, abordada nos relatos) da maneira como o enuncio (de onde vem o meu linguajar e o meu vocabulário). De onde vem minha inspiração minhas aspirações e meus desejos? (JOSSO, 2004, p. 26).

$\mathrm{Na}$ tentativa de responder às perguntas sugeridas pela pesquisadora, as narrativas autobiográficas docentes desvelam um modo particular de (re)lembrar e (re)contar a própria história de vida, inter-relacionando o eu, o outro e o mundo, caracterizando-se como espaço de reflexão, autoconhecimento e socialização da experiência vivida. Essa interface das pesquisas em Educação subsidiadas pelas narrativas configura-se, portanto, como espaço de pesquisa e formação, servindo, ao mesmo tempo, à produção de conhecimento e à autoformação do professor. Ademais, circunscrevem-se nos territórios em que os narradores partem das experiências de si, questionam os sentidos de suas vivências e aprendizagens, suas trajetórias pessoais e nas instituições escolares.

Segundo Goodson $(2000,2005)$, por meio das narrativas autobiográficas, os professores falam sobre o próprio trabalho, trazem à tona as dificuldades e dilemas vivenciados cotidianamente, desvelam a insegurança causada pela insuficiência da formação inicial, da falta de apoio institucional e de políticas públicas voltadas para o trabalho docente e revelam o risco diário de ter que lidar com as urgências e incertezas da prática. Essas interfaces das pesquisas autobiográficas trouxeram para o campo das pesquisas em Educação uma nova e fértil linha de investigação a respeito da formação de professores, da profissão professor e das práticas pedagógicas docentes.

Ao tomar como ponto de partida a experiência construída ao longo de uma trajetória, seja ela pessoal ou profissional, as narrativas autobiográficas docentes permitem a recordação de momentos e vivências da realidade cotidiana, ou seja, as recordações-referências (JOSSO, 2004), consideradas pelos professores como experiências significativas das suas aprendizagens, do seu desenvolvimento profissional e das imagens construídas de si e dos outros, levando-as a assumirem a condição de experiência formadora. 
A experiência emerge, portanto, como base das experiências formadoras, pois, ou a formação é experiencial, ou então, não é formação. Para que uma experiência seja considerada formadora "é necessário falarmos sob o ângulo da aprendizagem, essa experiência simboliza atitudes, comportamentos, pensamentos, saber-fazer, sentimentos que caracterizam uma subjetividade e identidades." (JOSSO, 2004, p. 47-48).

A autora categorizou as experiências formadoras em três modalidades: 1) "Ter experiências": os seres humanos têm experiências quando vivenciam os acontecimentos tornando-os significativos de forma não intencional; 2) "Fazer experiência": quando os seres humanos, de forma deliberada, provocam e criam situações, fazem experiências; 3) "Pensar sobre as experiências": quando refletem criticamente tanto sobre as experiências não intencionais quanto sobre as deliberadas, em outras palavras, quando pensam sobre suas experiências.

Assumindo que as experiências são as fontes das narrativas e que provocam mudanças na formação profissional docente, analisar as narrativas autobiográficas dos professores configura-se como um valioso instrumento de investigação para os pesquisadores interessados em compreender os processos de formação docente e desenvolvimento profissional, pois “[...] quem narra, narra-se... narrar narrando-se é um processo de construção identitário.” (FORMOSINHO-OLIVEIRA; FORMOSINHO, 2009, p. 17).

No entanto, para que as narrativas autobiográficas docentes de fato se configurem como uma poderosa estratégia para a formação de professores é indispensável que o processo de produção dessas narrativas seja direcionado e sistematizado com o intuito de criar condições para que os professores reflitam sobre sua própria formação e prática docente. Acerca disso, Souza (2006, p. 140) afirma que essa relação "dialética entre as dimensões prática e teórica, as quais são expressas através da metarreflexão do ato de narrar-se, dizer-se de si para si mesmo [é] como uma evocação dos conhecimentos das experiências construídos pelos sujeitos."

A reflexão emerge como elemento basilar das narrativas docentes, pois possibilita ao professor situar-se e sentir-se sujeito de sua própria ação, ampliando assim sua capacidade de buscar novos conhecimentos, lidar com as adversidades da prática docente, além de resolver os problemas cotidianos, na perspectiva de desenvolver-se profissionalmente, vez que, de acordo com Bolívar (2002), as narrativas docentes são caminhos investigativos para conhecer a prática quando oferecem elementos para sua compreensão, um meio para aprender com/na prática, pois possibilita a revisão e a crítica da ação, uma forma para (re)criar a prática, porque, ao repensá-la, o professor tem a oportunidade de criar, mudar e explorar os limites da experiência. 
Acerca disso, Abrahão (2004, p. 203) afirma que as narrativas autobiográficas “[...] são constituídas por narrativas em que se desvelam trajetórias de vida. Esse processo de construção tem na narrativa a qualidade de possibilitar a autocompreensão, o conhecimento de si, àquele que narra sua trajetória.” É nesse processo de reflexão e ressignificação de sua prática que o professor se constitui professor. Contudo, esse processo de constituição do ser professor, a partir da reflexão sobre a experiência vivida, em nenhum momento pode ser visto como uma (trans)formação sem crises, muito pelo contrário. O processo de narrar-se dialeticamente potencializa ao professor não apenas questionar-se, mas, sobretudo, inquietar-se, angustiar-se diante das contingências, incertezas, dúvidas, rupturas, instabilidades, complexidades, como aspectos determinantes da vida humana.

As narrativas docentes, portanto, configuram-se como espaços de/para a reflexão circunscritos em práticas coletivas (ZEICHNER, 2000, 2003, 2008). Primeiro porque o centro de toda prática reflexiva deve ser a ação docente em sua condição social. Segundo porque os professores devem reconhecer que suas ações são políticas e que, por isso, podem e devem ser reconfiguradas de acordo com suas perspectivas pessoais e profissionais. E, finalmente, porque a prática reflexiva, enquanto prática social, demanda a coletividade e não a individualidade, revelando a necessidade de criação de comunidades de aprendizagem nas escolas e nas universidades de forma que os professores possam se apoiar e se estimular.

Ademais, o uso das narrativas autobiográficas como estratégias para a produção de dados de pesquisas com abordagem qualitativa não apenas possibilita ao professor organizar suas ideias para produzir seu(s) relato(s) escrito(s) ou oral(is), mas também reconstruir e dar sentido pessoal às suas experiências de vida de modo reflexivo, pois "a experiência de vida e a trajetória anterior do professor ou professora contribuem para formar a sua visão de ensino e os principais elementos da sua prática." (GOODSON, 2005, p. 307).

A produção de narrativas autobiográficas oportuniza aos professores falarem de si, além de envolverem a reflexão sobre a experiência vivenciada, visto que podem conhecer a realidade social e aprofundar sua relação com essa realidade. "O processo de falar de si para si mesmo" (SOUZA, 2004) possibilita que os professores revelem seus conhecimentos, pensamentos e sentimentos, contribuindo assim para que possamos compreender sua visão de mundo, de ensino e de aprendizagem, e, principalmente, entendermos as teorias implícitas em sua ação pedagógica, produzidas a partir de suas próprias experiências do cotidiano escolar, possibilitando desse modo a aprendizagem e o desenvolvimento profissional da docência. 


\section{FALAR DE SI E DO OUTRO, ESCREVER SOBRE SI E SOBRE O OUTRO: O CONHECIMENTO DE SI}

As experiências vivenciadas por Alice tanto no País das Maravilhas quanto no Mundo do Outro Lado do Espelho configuram-se como pistas para ajudá-la a se autodescobrir e se autoconhecer. Ao reconhecer e compreender essas pistas fornecidas pela interação com as personagens inóspitas com as quais se depara em seus sonhos, a menina torna-se capaz de lidar com as adversidades e incertezas enfrentadas em suas aventuras em ambos os mundos.

Souza (2004, p. 4) salienta que "história é que nem fio: a gente tece e o fio cresce, a gente inventa e tudo o que a gente tenta se transforma em coisa nova." De fato, reviver memórias, falando sobre elas, demanda muito zelo e cautela, pois implica relembrar e reviver não apenas fatos bons e felizes de nossas vidas, mas também acontecimentos ruins e tristes. É como reabrir janelas há tempos fechadas, sem a intenção de realmente abri-las. Se falar sobre nossas lembranças não é tarefa fácil, o que dizer sobre registrá-las por escrito? Há quem diga que pode ser ainda pior, pois escrever é uma habilidade ainda mais elaborada do que falar. Há quem diga que é ainda melhor, pois permite a elaboração prévia e articulação consciente das narrativas. Seja qual for, é sempre um desafio produzir memórias, sejam elas de que natureza forem.

Os excertos desta seção revelaram as experiências formadoras vivenciadas pelos colaboradores no período de realização da pesquisa e potencializadas não apenas pelo engajamento no grupo e produção/socialização das narrativas orais e escritas nas ocasiões dos encontros interativos, mas também pela oportunidade ímpar de produção individual e coletiva de novos saberes, sobretudo os autobiográficos, por meio do caminhar para si, possibilitando assim o (re)conhecimento de si enquanto ser ativo, autônomo e responsável pela própria aprendizagem e desenvolvimento profissional.

\subsection{FALAR DE SI E DO OUTRO: OS ENCONTROS INTERATIVOS}

A decisão de utilizar as narrativas autobiográficas orais e escritas para investigar o processo formativo dos colaboradores ao se tornarem iniciantes na docência universitária constituiu-se a tônica teórico-metodológica dessa pesquisa. A opção por combinar fala e escrita justifica-se porque embora a "[...] fala possa originar uma primeira versão de uma narrativa, essa evolui e se qualifica pela escrita.” (MORAES; GALIAZZI, 2003, p. 12). 
As narrativas orais produzidas nos encontros interativos configuraram-se como uma estratégia diferenciada, formativa e privilegiada para o falar de si e falar do outro, pois funcionaram como espaço ímpar para que os colaboradores contassem, ouvissem e discutissem não apenas suas histórias, mas também as histórias dos demais membros do grupo.

Nessa perspectiva, o Coelho Branco refletiu:

Porque eu acho que quando há troca de experiências [...] Quan-
do eu passar por dificuldades eu vou lembrar e vou saber lidar
melhor, é como as reuniões do AA em que eles trocam expe-
riências constantemente [...] nos momentos de dificuldade vai
ajudar, eu vou lembrar das experiências e ver que pode me-
lhorar. [...] Estou ansioso para ver o trabalho pronto, eu quero
chegar ao final do memorial e ver tudo realmente que eu fiz
dentro da universidade escrito bem bacana, maravilhoso, a cada
encontro vou lembrando um acontecimento novo. (Fala do Co-
elho Branco no oitavo encontro).

$\mathrm{Na}$ pesquisa realizada, falar de si configurou-se como um dispositivo de (auto)formação, pois durante as conversas as narrativas foram utilizadas como mecanismo que oportunizou aos colaboradores tornarem-se "pesquisadores de si" (OLIVEIRA, 2000). Como pesquisador de si, o Coelho Branco refletiu sobre as marcas deixadas nele pela experiência em participar do grupo.

Pensar a respeito do que essas marcas fizeram com ele e depois pensar sobre o que ele poderia fazer a partir de então alinha-se à perspectiva de Josso (2004), ao defender que é essa reflexão sobre o que foi vivenciado que a transforma em experiência formadora. Refletir referente a essa experiência foi, portanto, imprescindível para o processo formativo do Coelho Branco, trazendo em seu bojo aprendizagens profissionais, pois, segundo a pesquisadora francesa, a experiência somente é formadora quando há aprendizagem.

Compartilhar as aprendizagens acerca da produção das narrativas autobiográficas e da participação do grupo possibilitou que as histórias e experiências deixassem de ser apenas do Coelho Branco e passassem a fazer parte das vidas dos demais colaboradores da pesquisa. É possível inferir, portanto, que se engajar no grupo, expor-se durante os encontros interativos, compartilhar suas experiências e apropriar-se das experiências dos demais colaboradores, potencializou o desenvolvimento profissional do professor.

Em sua narrativa, o Coelho Branco também ressaltou a possibilidade formativa dos diálogos autobiográficos como gatilhos de memória, pois ouvir as falas dos demais membros do grupo, além de potencializar reflexões individuais e coletivas, despertou nele lembranças que não haviam sido contempladas em seu memorial e que, por 
razões conhecidas (ou não), até aquele momento estavam esquecidas. Nas palavras de Josso (2004, p. 130), esse movimento “[...] faz parte do processo de formação; ele dá sentido, ajuda-nos a descobrir a origem daquilo que somos hoje. É uma experiência formadora que tem lugar na continuidade do questionamento sobre nós mesmos e de nossas relações com o meio." A memória configura-se, portanto, como ferramenta importante para a (re)construção e (res)significação das experiências formadoras vivenciadas pelos professores e compartilhadas por suas narrativas autobiográficas em contexto investigativo-formativo, como, por exemplo, as conversas interativas.

Nessa perspectiva, o movimento de tomada de consciência e de compreensão de si permite que os professores percebam outros desafios, outros caminhos e oportunidades em um processo contínuo de aprendizagem pessoal e profissional. Assim, o compartilhamento das recordações-referências e a vivência coletiva de experiências formadoras possibilitaram ao Coelho Branco um reencontro com suas histórias e memórias, desvelando não apenas o "caminhar para si”, mas também o "caminhar para/com o outro" na expressão de Josso (2004).

Sobre as possibilidades formativas das narrativas orais, a Rainha Vermelha comentou:

Aqui nós temos muitas possibilidades de discutir coisas que acontecem conosco, às vezes, certos acontecimentos que nem conseguimos entender direito ou deixamos passar sem perceber, assim, pensar sobre tais fatos e mais ainda poder discuti-los é uma maneira de se tornar não só alguém melhor, mas também professor melhor. (Fala da Rainha Vermelha no primeiro encontro).

Essa narrativa coaduna-se às pesquisas de Josso (2004) Pineau (2006), Delory-Momberger (2008), entre outros, pois se engajar no grupo oportunizou à Rainha Vermelha sentir-se sujeito ativo não apenas de sua própria história, mas também das dos demais membros do grupo, fomentando sua capacidade de produzir novos conhecimentos para lidar com as dificuldades da prática cotidiana. Refletir a respeito de suas ações e pensamentos em contexto formativo-investigativo, portanto, permitiu que a colaboradora não apenas compreendesse melhor sua própria prática, mas também (re)construísse sua trajetória formativa de forma introspectiva, retrospectiva e prospectiva.

Nas palavras de Cunha (2007, p. 18):

[...] organizar narrativas destas referências é fazê-lo viver um processo profundamente pedagógico, onde sua condição existencial é o ponto de partida para a construção de seu desempenho na vida e na profissão. Através da narrativa ele vai descobrindo os significados que tem atribuído aos fatos que viveram, e, assim, vai reconstruindo a compreensão que tem de si mesmo. 
A narrativa da Rainha Vermelha confirmou que formar-se demanda, além da troca de experiências, relações interpessoais e aprendizagens pessoais, pois " [...] os docentes geram conhecimento prático a partir da sua reflexão sobre a experiência." (GARCIA, 1999, p. 4). Partilhar experiências com os demais membros do grupo constituiu-se, portanto, uma fonte de aprendizagem para o trabalho docente para a colaboradora. A fala da professora enfatizou também o papel das narrativas orais como uma forma ímpar de comunicação, pois comunicar-se implica saber argumentar, justificar, dialogar e também ouvir, habilidades necessárias para a docência em todos os níveis de ensino.

Quanto às experiências vivenciadas nos encontros, a Rainha Branca disse e escreveu:

Após terminar a leitura da minha carta, Renata me perguntou
sobre a questão do trauma de alguns alunos referentes à Lín-
gua Inglesa que eu havia mencionado na carta. Logo respondi
que já fazia um tempo que eu observava esta questão, porém à
medida que nossos encontros iam passando para falar de nos-
sas reflexões sobre ser professor, passei a olhar com uma visão
diferente, talvez com um olhar mais crítico. (Quarta carta da
Rainha Branca) Porque com certeza quando a Rainha Vermelha
e o Coelho Branco começarem a ler os deles [memoriais], eu
vou me lembrar como eu já lembrei hoje de um fato que acon-
teceu comigo, né! Eu posso complementar, não posso? [Renata:
pode, pode!] As cartas também, não é? (Fala da Rainha Branca
no primeiro encontro). [...] Agora esse fim de semana para eu
terminar foi simplesmente [...] Eu sentei mais ou menos meia
noite e eu parei de escrever porque eu simplesmente, disse as-
sim "meu Deus", era duas e meia da manhã! Porque assim eu
me surpreendi porque eu não estava com sono, não estava can-
sada, entendeu? Fui escrevendo! Então assim, foi engraçado,
porque quando a gente começa a escrever, a gente começa a se
lembrar e justamente o porquê dessa primeira aqui [...] eu achei
muito importante isso [...] eu tive vontade de colocar lá no final
que eu não quero parar o meu memorial aqui! Daqui a muitos
anos eu quero publicar um memorial que seja de muitas pági-
nas, para relatar todos os [...] as memórias, né, as experiências!
Eu não sei vocês, mas comigo tudo o que eu aprendi, tanto em
teoria, eu aprendi ou lendo ou observando os meus professores!
Então eu espero que o meu memorial sirva como inspiração,
para essas pessoas que também não têm experiência, que eles se
baseiem na minha. (Fala da Rainha Branca no quarto encontro).

A revisão da literatura confirmou que, entre os vários desafios enfrentados pelos professores universitários, a dificuldade em compreender as reais interfaces da profissão nesse nível de ensino, é um dos maiores, sobretudo, porque não existe uma 
formação específica para assumir a docência universitária. De acordo com Pimenta e Anastasiou (2005), esse é o cerne da problemática profissional do Ensino Superior, pois a maioria dos docentes não tem ciência do que é ser professor nesse nível de ensino, mesmo os licenciados, como revelaram os colaboradores da pesquisa.

Zabalza (2004, p. 144) enfatiza que “[...] o exercício da profissão docente requer uma sólida formação, não apenas nos conteúdos científicos próprios da disciplina, como também nos aspectos correspondentes à sua didática e ao encaminhamento das diversas variáveis que caracterizam a docência." Por isso, o professor deve sempre investir em sua formação para continuar questionando, refletindo, (re)construindo, (re)criando suas práticas para produzir novos saberes e conhecimentos em momentos de troca e de discussão com seus pares como nos encontros interativos, como sinalizou a colaboradora.

O primeiro trecho do fragmento revelou que participar do grupo de pesquisa possibilitou que a Rainha Branca ampliasse seu repertório de saberes didático-pedagógicos também nas dimensões éticas e afetivas da docência, possibilitando-lhe desenvolver suas habilidades, atitudes e valores relacionados à sua vida pessoal e profissional (GALVÃO, 2005; SUÁREZ, 2008). É possível inferir, portanto, que se engajar nas conversas também potencializou seu desenvolvimento profissional.

A exemplo da Rainha Vermelha, a Rainha Branca também valorizou a socialização das narrativas escritas (memoriais e cartas) e a participação nas conversas interativas como preciosos "gatilhos de memória", pois por meio delas lembranças e recordações puderam ser recuperadas, bem como detalhes da própria história que estavam guardados (ou esquecidos mesmo) em suas mentes. Nas palavras de Josso (2004, p. 44), “As experiências de transformação das nossas identidades e da nossa subjetividade são tão variadas que a maneira mais geral de descrevê-las consiste em falar de acontecimentos, de atividades, situações ou de encontros que servem de contexto para determinadas aprendizagens."

Essa potencialidade das narrativas alinha-se às ideias de Benjamin (1994) acerca do papel central da memória para a recomposição da experiência humana, posto que narrar implica articular a memória ao ato de lembrar, tornando a experiência comunicável, além de motivar a reflexão sobre os acontecimentos e vivências compartilhados.

No fragmento final da narrativa, a colaboradora compartilhou suas impressões e reflexões sobre a escrita do memorial, consolidando-a não apenas como um "lugar de memória” (NORÁ, 1993), mas também criando espaços para que os colabora- 
dores expressassem e compartilhassem as suas próprias reflexões e sentimentos acerca desta, fortalecendo assim o contexto investigativo-formativo da pesquisa realizada.

Ao compartilhar o processo de escrita de seu memorial, a Rainha Branca destacou seu empenho e empolgação para finalizá-lo, além de enfatizar o desejo de transformá-lo em livro a fim de compartilhá-lo com outros professores.

Nas palavras de Prado, Ferreira e Fernandes (2011, p. 145), “[...] a publicação dos textos produzidos pelos que de fato constroem a educação, narrando suas experiências, revelando suas ideias, analisando o que fazem, é uma conquista de toda a categoria profissional. Quando um educador torna públicos os seus textos, todos ganhamos." Essa tomada de decisão revelou não apenas a boa vontade da colaboradora em compartilhar suas memórias com outras pessoas, além dos membros do grupo, mas também sua intenção em ajudar outros professores universitários, também iniciantes na profissão, permitindo-lhes conhecer, além de sua trajetória formativa até o ingresso no magistério superior, suas alegrias e frustrações vivenciadas nesse nível de ensino.

Dentre as reflexões sobre a visita ao passado em busca de memórias dos colaboradores emergiu um importante ponto de convergência: produzi-las aguçou, mexeu e provocou questionamentos em cada um deles não apenas sobre as experiências selecionadas, mas também sobre a razão pelas quais elas marcaram suas vidas, assumindo-se, de fato, como "[...] pessoas que reconhecem seu engajamento num projeto comum de pesquisa formação através da prática de narrativas autobiográficas.” (PASSEGGI, 2008, p. 44).

Reis (2008) ressalta que ao lerem, analisarem e discutirem os memoriais de um docente, os professores-leitores atribuem-lhes formas próprias de pensar, sentir e agir, apropriando-se dessas histórias de forma particular e única, respaldando-se para isso em suas próprias experiências, retirando delas o que considerarem mais significativo. Pensar sobre isso possibilitou que os colaboradores reconstituíssem memórias como sujeitos críticos de sua própria história.

Compartilhar narrativas, apesar da distância entre autor e leitor, permite a aproximação entre ambos, pela identificação com as experiências descritas. Ou seja, as narrativas de professores mais experientes configuram-se como fonte influente de inspiração e conhecimento, estimulando os professores-leitores a refletirem não apenas a respeito da profissão, mas também a respeito de suas práticas docentes.

É possível inferir, portanto, que, em virtude do desejo de publicar suas histórias e memórias, com a intenção de ajudar outros professores iniciantes na docência universitária, a Rainha Branca não apenas reconheceu, mas, sobretudo, valorizou essa interface formativa das narrativas docentes, que, de acordo com Ibiapina (2008, p. 86), 
[...] permite[m] a reconstrução da profissão docente, permitindo que as lembranças sejam reorganizadas, à medida que se traz fatos passados para o presente, a fim de serem reinterpretados. Favorece também processos formativos, a prática reflexiva e a articulação teoria e prática.

Em contexto investigativo, quando falaram de si com os outros e falaram dos outros para si, os colaboradores (re)construíram diálogos autobiográficos, assumindo o protagonismo de suas histórias e reflexões, tornando-se, ao mesmo tempo, autores e intérpretes de suas próprias experiências, apoiando-se para isso em suas memórias e lembranças, mas não as reproduzindo mecanicamente, mas reconstruindo-as reflexivamente com os olhos do presente.

Falar de si e do outro possibilitou o compartilhamento voluntário de reflexões, sentimentos, expectativas, entre outros, constituindo-se um espaço fértil e privilegiado para fomentar novas reflexões, sentimentos, expectativas, entre outros, não apenas sobre a iniciação à docência universitária (desenvolvimento profissional), mas principalmente sobre o "caminhar para si" (desenvolvimento pessoal) dos colaboradores.

\subsection{ESCRITAS DE SI E DO OUTRO: OS MEMORIAIS DE FORMAÇÃO E AS CARTAS NARRATIVAS}

Na perspectiva biográfico-narrativa, escrever sobre si também se configura como um espaço de aprendizagem e desenvolvimento profissional docente. De acordo com Souza (2006), produzir narrativas escritas demanda do professor a capacidade de manusear sua língua materna para escolher e ordenar as palavras de modo que essas possam expressar da forma mais adequada e aproximada seus modos de pensar, sentir e agir.

Nas palavras escritas, os professores podem, portanto, vislumbrar o reflexo das experiências vivenciadas ao longo de sua trajetória formativa, pois para registrar por escritos essas experiências formadoras eles precisam, além de encontrar as palavras certas, refletir sobre sua trajetória de vida, repleta de alegrias, certezas e possibilidades, mas também de tristezas, incertezas e limitações. Com essa intenção, os colaboradores foram convidados a escrever, além de cartas narrativas, seus memoriais de formação.

Sobre as aprendizagens adquiridas e os sentimentos vivenciados ao produzir esses instrumentos, o Coelho Branco escreveu e falou:

Chego ao final da escrita destas memórias com uma sensação muito grande de felicidade. Depois de relembrar tantos fatos que estão guardados na memória, foi possível perceber minha evolução e felizmente, de forma positiva. O processo de escrita destas memórias serviu para reviver muitas experiências 
do passado e refletir na forma como foram conduzidas e me fizeram pensar na minha atuação, levantando hipóteses que me fizeram indagar que se poderia ter feito diferente ou deixado de fazer. [...] Confesso que algumas histórias ficaram de fora, procurei selecionar as mais marcantes para colocá-las aqui para vocês. Espero que estas lembranças possam ajudar ou até mesmo inspirar a quem possa interessar, principalmente jovens professores em início de carreira, que, como eu, almejam uma educação melhor e mais igualitária para nosso país. (Memorial do Coelho Branco) [...] Depois de ler o memorial, Rainha Branca relatou que esta atividade a ajudou muito a pensar no que já foi, no que é e no que ela quer ser. O memorial ajuda a eternizar o passado e segundo ela foi maravilhoso escrever. Eu compartilho deste sentimento com ela e posso afirmar que é muito bom mesmo. Passei alguns meses para escrever o meu. Fiz devagarzinho, selecionando o que poderia ser interessante de ser falado e agora chegou o momento de compartilhar com vocês. Vamos lá então. Espero que tenham gostado de ler sobre minha história e estou pronto para ouvir suas impressões. (Quinta carta do Coelho Branco) Logo no início Renata chamou atenção para uma parte do que foi lido: "[...] e até mesmo enxergar em minhas vivências coisas que não havia visto no momento em que vivenciei a situação." (SOARES, 2001). Esta colocação reflete bem todo o processo da escrita de nossos memoriais, que nos permite voltar ao passado e até mesmo entender o porquê de algumas consequências de decisões tomadas e esta reflexão nos ajuda hoje, quando estamos mais maduros, mas ainda nos deparamos com decisões a serem tomadas e consequências a serem enfrentadas. (Oitava carta do Coelho Branco) Agora em relação à carta, o pensamento principal que eu tive foi um entusiasmo em colocar todas essas experiências no papel porque iam ficar perdidas no ar, pois a memória da gente não é tão poderosa. (Fala do Coelho Branco no primeiro encontro).

Tal fragmento confirma que narrar transcende informar, implica, acima de tudo, compreender quem somos e como nos tornamos o que somos no presente. A produção dessas narrativas escritas possibilitou ao colaborador empreender uma viagem no tempo cujo ponto de partida foram as seguintes questões: Que professor eu fui/era? Que professor eu sou? Que professor eu serei? As escritas de si, portanto, auxiliaram o colaborador a ampliar sua capacidade de pensar, avaliar e analisar o que não apenas o que fez e faz, mas também fazer projeções para o futuro, remetendo-o, na perspectiva de Souza (2004, p. 75), a uma dimensão de "auto escuta de si mesmo, como se estivesse contando para si próprio suas experiências e aprendizagens que construiu ao longo da vida, através do conhecimento de si."

A reflexividade biográfica emergiu como um dispositivo indispensável para o processo, sem o qual o Coelho Branco não teria sido bem-sucedido em sua viagem. Zeichner (2003) enfatiza que refletir sobre a própria prática não é um processo espontâneo 
do professor. Deve ser, além de uma ação intencional, potencializada também por um (ou mais de um) dispositivo(s) externo(s), como no caso da pesquisa: a produção de narrativas autobiográficas sobre a vida pessoal e o início da docência no Ensino Superior.

As narrativas indicaram também que o Coelho Branco tinha consciência das implicações da exposição de suas histórias e memórias escritas, e que, em virtude disso, optou deliberadamente por expô-las de forma cautelosa e planejada, revelando um sentimento de prudência. Lima (2006, p. 128) esclarece que “[...] a prudência está orientada pelo medo de errar, pela vontade e responsabilidade por acertar." Os depoimentos do colaborador revelaram, portanto, a tênue relação entre prudência e memória, pois ser prudente no campo autobiográfico implica a seleção e até mesmo censura das histórias a serem compartilhadas. Revisitar o passado, portanto, ofereceu subsídios, por meio de experiências prévias, para encaminhar comportamentos e condutas do colaborador basilares para seu desenvolvimento profissional.

A exemplo da Rainha Branca, o Coelho Branco demonstrou grande interesse e alegria em socializar seus escritos não apenas com o grupo, mas com outros professores, interessados em conhecer suas histórias e memórias e também dispostos a aprender com elas. Com essa intenção, o colaborador demonstrou não apenas valorizar, mas também querer dar maior visibilidade à sua produção intelectual, atitude bastante louvável e admirável que deve ser seguida por todos os profissionais da educação, vez que, "infelizmente, ao longo da história, o magistério foi tão desqualificado que, [...] a grande maioria dos educadores considera que suas experiências não têm importância suficiente para serem documentadas e se tornarem públicas." (PRADO; FERREIRA; FERNANDES, 2011, p. 146).

No trecho final da narrativa, o Coelho Branco reportou-se especificamente à escrita das cartas narrativas, gênero autobiográfico utilizado com a intenção de, durante a escrita, provocar nos colaboradores momentos de retrospecção e reflexão sobre as recordações-referências que marcaram sua trajetória formativa, não apenas no que se refere à escrita do memorial e das cartas, mas de todo o processo vivenciado no grupo de pesquisa (CHENÉ, 1988; JOSSO, 2004, 2010; DOMINICÉ, 2008). É possível inferir, portanto, que escrever as cartas, registrando suas recordações e reflexões por escrito, possibilitou-lhe não apenas revisitar suas histórias e memórias, mas também compreender por que foram internalizadas a sua forma de pensar, sentir e agir.

Sobre as possibilidades formativas das narrativas escritas, a Rainha Vermelha escreveu:

E como é possível aprender com as experiências dos outros, é através deste memorial, dividindo momentos com meus cole- 
gas que viso me tornar alguém melhor e até mesmo enxergar em minhas vivências coisas que não havia visto no momento em que vivenciei a situação. [...] Escrever estas memórias me fizeram refletir muito sobre meus saberes docentes e do quanto eu ainda tenho que melhorar. Sei que este memorial ainda não está encerrado, pois todas as vezes que eu o olho incluo algo novo, mas ao final dele tenho a completa certeza de que estou na profissão certa e de que nem uma outra me faria um ser humano tão feliz quanto eu sou. (Memorial da Rainha Vermelha) Voltando ao memorial da Rainha Branca me identifiquei com ele por diversas vezes, temos muita coisa parecida. A leitura dele me fez lembrar coisas minhas para colocar no memorial sem fim, como eu chamo o meu! [...] Essa minha carta é bem mais curta porque tudo que tinha na cabeça escrevi no memorial! Eu preciso dizer que exercício maravilhoso foi escrever este memorial, me fez refletir e pensar, além de que revendo o que aconteceu pude enxergar pontos que antes não tinha visto. (Quarta carta da Rainha Vermelha).

A exemplo do Coelho Branco, a narrativa da Rainha Vermelha destacou a possibilidade de compartilhar experiências e de aprender com os demais como interface importante das escritas de si para si, corroborando as palavras de Souza (2004, p. 412), pois "o ato de lembrar/narrar possibilita ao ator reconstruir experiências, refletir sobre dispositivos formativos e criar espaço para uma compreensão da sua própria prática." As narrativas da colaboradora revelaram, portanto, não apenas os conhecimentos construídos ao longo de sua vida e do exercício da docência, mas também suas próprias reflexões e percepções sobre o percurso, fundamentais para sua (auto) formação pessoal e profissional.

A consciência de sua incompletude também emergiu dos escritos da colaboradora, coadunando-se com a visão freireana de que "onde há vida, há inacabamento. Mas só entre homens e mulheres o inacabamento se tornou consciente.” (FREIRE, 1996, p. 55). É perceptível que a Rainha Vermelha reconhecia-se como inconclusa, em constante processo de formação, "fazendo-se e refazendo-se no processo de fazer a história, como sujeito" (FREIRE, 1996, p. 91), a partir das experiências vivenciadas nos mais diversos contextos formativos, como, por exemplo, em casa, na escola, no trabalho, entre outros.

É possível inferir que sentimento de inconclusão tenha sido ocasionado, ou quem sabe até mesmo acentuado, por sua visível insatisfação consigo mesma, demonstrada por sua necessidade de sempre buscar a perfeição, alinhando-se a Freire (1996, p. 135), vez que “[...] é possível saber melhor o que já sabe, e reconhecer o que ainda é necessário aprender." As narrativas indicaram, portanto, que Rainha Vermelha, ao mesmo tempo que tem consciência que é possuidora de diferentes saberes e conhecimentos, reconhece suas limitações, pois sabe que ainda há muito a ser aprendido. 
Os depoimentos da colaboradora confirmaram que escrever as memórias em contexto investigativo se configura como uma possibilidade formativa, posto que oportunizou aos professores “[...] evidenciar emoções, experiências ou pequenos fatos marcantes, dos quais antes não nos tínhamos apercebido.” (FREITAS; GALVÃO, 2007, p. 220). Não apenas o processo de rememoração das recordações-referência para a escrita do memorial e das cartas, mas também o compartilhamento desses escritos em grupo possibilitou-lhe reconstruir, de forma crítico-reflexiva e com os olhos do presente, sua trajetória formativa pessoal e profissional, transformando-os em poderosos dispositivos de formação docente.

A exemplo do Coelho Branco, a socialização dos memoriais e das cartas como espaços e momentos para a socialização não apenas de conquistas e alegrias, mas também de pensamentos, dúvidas e sentimentos também emergiu dos fragmentos da Rainha Vermelha. É perceptível uma aproximação dessas reflexões da colaboradora com os escritos acerca do compartilhamento de configurar-se com dispositivo privilegiado para a construção de si mesmo a partir das relações com os outros, pois nas palavras de Nóvoa (1992, p. 9) “formar é sempre formar-se.” A autoformação materializa-se, portanto, na interação com os outros, conforme salientou a colaboradora.

Acerca do processo de produção dos memoriais e das cartas, a Rainha Branca relatou:

Finalmente, fiquei feliz em dividir com vocês, um pouco da minha história. Pensei e pensei inúmeras vezes para tentar não deixar passar as melhores e mais significativas lembranças de minha vida. Espero que este memorial sirva para todos como modelo a ser seguido, ou uma fonte de inspiração, afinal, para quem não tem experiência, ler e observar são fatores imprescindíveis para começar uma carreira. (Memorial da Rainha Branca) Depois da minha leitura, vi que precisava corrigir algumas coisas e acrescentar muitas outras, que acabaram passando despercebidas e que me lembrei posteriormente. Tenho certeza que quando eu ler os memoriais do Coelho Branco e da Rainha Vermelha irei ainda lembrar de muitas outras coisas. Isto é o que mais me deixou feliz, pois acredito que ao longo da minha vida não iria me recordar de tantas coisas boas e de outras nem tanto. (Quinta carta da Rainha Branca) Hoje escrevo de forma bem diferente das anteriores, porque tive um problema com meu computador e não tive tempo para mandar formatá-lo, porém, relembrei das inúmeras cartas que escrevia a mão, antes da explosão e acesso aos computadores e confesso que bateu saudades de alguns amigos que eu me comunicava com cartas com essa, bons tempos aqueles! (Sexta carta da Rainha Branca) Eu comecei a escrever de forma tão natural e a preocupação era escrever para colaborar com o seu trabalho, ai foi tão gostoso assim escrever que eu acabei depois pensando nos meus alunos pensei muito na questão do Coelho Branco e da Rainha Vermelha, foi assim uma mixagem 
de tudo acabou juntando preocupação com o seu trabalho não foi difícil foi prazeroso, foi rápido, a gente acaba pensando muitas coisas. (Fala da Rainha Branca no segundo encontro). Acho que a gente tem essa questão da troca de experiências e também essa questão do melhorar, eu acho que aqui nós vamos melhorando e com a ansiedade a gente vai querendo acrescentar coisas, até porque quando você vive alguma coisa você sempre quer acrescentar, por exemplo, se eu ler o memorial de novo eu vou querer acrescentar coisas novas, através daquilo que a gente já escreveu a gente vai lembrando de pequenas coisas e vai tentando melhorar. (Fala da Rainha Branca no oitavo encontro).

Antes de se dedicar ao processo de escrita, é preciso que o professor-autor seja estimulado a enveredar-se pelos meandros de suas recordações e lembranças para depois, deliberadamente, narrar suas histórias e memórias. Para a Rainha Branca, a mola propulsora para a escrita de seu memorial foi a alegria e o contentamento em poder socializá-lo com os membros do grupo e o desejo latente de compartilhá-lo com outros professores iniciantes na carreira universitária, corroborando as ideias defendidas por Goodson (2000) sobre a relevância da voz do professor ser ouvida, especialmente quando falam do seu trabalho, de modo que o narrador assuma o protagonismo de suas memórias e histórias.

As reflexões iniciais acerca das escritas de si da colaboradora alinham-se às ideias de Souza (2008), quando ressalta que escrever sobre si não é nem uma atividade mecânica nem técnica; é, além de uma forma de conhecimento de si, um meio de transformação de si, potencializado pela valorização da subjetividade e das experiências formadoras. É possível inferir, portanto, que as escritas de si para si mesma oportunizaram à Rainha Branca escutar a si própria para refletir a respeito de suas recordações-referências antes/durante/depois de registrá-las em seu memorial.

Na sequência de sua narrativa, a colaboradora evidenciou outra interface basilar das escritas de si: a assunção de papéis duplos e simultâneos, narradora e leitora. Antes de compartilhar seus escritos com o grupo, ela foi a primeira leitora de suas memórias, “[...] assum[indo] o papel de analista do já escrito [permitindo-se], por assim dizer, o controle de qualidade, do ponto de vista do conteúdo da forma. Aquele que escreve tem de ser, quase ao mesmo tempo, autor, leitor e revisor.” (PRADO; SOLIGO, 2007, p. 34). Tornar-se autora e escritora de suas histórias e memórias demandou uma releitura cuidadosa do mundo, exigindo da Rainha Branca um compromisso com seu próprio texto, refinado não apenas durante sua escrita, mas, sobretudo, durante sua leitura seletiva.

Em uma passagem posterior da narrativa, a colaboradora ateve-se a um momento específico do processo formativo-investigativo em que, por razões técnicas, precisou escrever uma de suas cartas de forma tradicional, ou seja, manuscrita. O de- 
poimento revelou seu saudosismo do tempo em que a comunicação não era tão fortemente mediada pela tecnologia eletrônica como hoje em dia, corroborando os estudos de Galvão e Gotlib (2000) acerca do desuso ou quase extinção desse gênero textual.

Muito embora as cartas sejam sempre redigidas para um destinatário, contribuem para a formação do remetente porque, a exemplo dos memoriais, escrever demanda do autor não apenas o registro escrito, mas também ler e pensar sobre o que foi escrito. A escrita de si demanda, assim, a reflexão do próprio autor, o pensar sobre si mesmo, revelando-se como uma estratégia autoformativa, conforme destacado pela colaboradora.

Alinhando-se à perspectiva de Souto Maior (2001), Cunha (2002), Silva (2002), entre outros, o depoimento da Rainha Branca confirmou que escrever cartas possibilitou uma maior aproximação com sua própria história e com as histórias dos demais membros do grupo, pois fomentou o intercâmbio de informação e aproximou autora e leitores ao compartilharem suas histórias e memórias, abrindo espaço para a imaginação, empatia, cumplicidade, alteridade e solidariedade.

Escritas de si, escritos autobiográficos, escrita autorreferencial, narrativas autobiográficas escritas; enfim, são múltiplas as expressões que congregam o gênero de escrita em que o professor-autor escreve sobre si mesmo, a fim de potencializar seu desenvolvimento pessoal e profissional, vez que, por meio da escrita, "o sujeito pode refletir e construir conhecimento explícito e a consciência metacognitiva, pela possibilidade de verificação do discurso escrito enquanto produto de pensamento, de objetivação da experiência pessoal.” (OLIVEIRA, 2000, p. 154). Nessa perspectiva, escrever sobre si para si mesmo fomenta o autoconhecimento, potencializando assim o caminhar para si.

Ao olharem para si e também para o outro quando escreveram suas histórias e memórias estimulou os colaboradores a refletirem não apenas a respeito de sua trajetória formativa, mas também a (re)conhecerem os momentos-charneira que os encaminharam para novas direções, especialmente na universidade como acadêmicos e depois como professores iniciantes, evidenciando assim o potencial formativo das narrativas autobiográficas escritas.

A socialização dos memoriais de formação e das cartas narrativas nas conversas interativas promoveu identificação entre os colaboradores, pois muitas das memórias narradas por cada um deles se aproximavam de situações vivenciadas pelos demais, configurando-se assim como potentes "gatilhos de memória" que, entre outros, (re)encaminharam tanto os escritos que já haviam sido produzidos até aquela ocasião quanto os que seriam produzidos a posteriore.

As narrativas escritas compartilhadas no grupo oportunizaram, portanto, o encontro dos colaboradores para compartilharem experiências, saberes e reflexões, 
abrindo, além de um novo campo de possibilidades e problematizações, um novo espaço para a ressignificação de experiências, reelaboração de outras práticas e compreensão da própria prática docente. Isso porque, foram estimulados a desenvolver uma atitude crítico-reflexiva (ZEICHNER, 2000), assumindo-se como professores reflexivos diante da retrospectiva de sua trajetória de vida e participação no grupo de pesquisa.

Os colaboradores também (re)conheceram a importância de registrar por escrito suas narrativas autobiográficas, eternizando, assim, suas histórias e memórias, tornando-as leituras privilegiadas não apenas para si mesmos e os demais membros do grupo, mas também para outros professores iniciantes, porque "a escrita é uma arma poderosa, senão por outra razão, porque seu destino é a leitura. A escrita documenta. Comunica. Organiza. Eterniza. Subverte. Faz pensar. A nós mesmos e aos leitores." (SOLIGO; PRADO, 2007, p. 35).

Em suas narrativas, os colaboradores escreveram também a respeito das mudanças pelas quais passaram ao longo de suas trajetórias ilustrando-as, especialmente com exemplos sobre o início da docência universitária, reportando-se ao que fizeram e a como pensavam nesse período e como essas ações e pensamentos foram revisitados e refletidos no contexto formativo-investigativo da pesquisa. Nas palavras de Zabalza (2004, p. 10).

[...] escrever sobre o que estamos fazendo como profissional (em aula ou em outros contextos) é um procedimento excelente para nos conscientizarmos de nossos padrões de trabalho. É uma forma de "distanciamento" reflexivo que nos permite ver em perspectiva nosso modo particular de atuar. É, além disso, uma forma de aprender.

Corroborando as ideias destacadas pelo autor, ao escreverem sobre si, para si e para o outro, cada colaborador narrou em seus textos autobiográficos não apenas acontecimentos pessoais, mas também aqueles relacionados à escolha da docência, à vida acadêmica, e, sobretudo, ao exercício da docência universitária e à participação do grupo, conforme foram solicitados. Para tanto, cada professor precisou revisitar, avaliar e (re) organizar suas histórias e memórias, revelando, assim, seus olhares sobre si mesmos, seus desejos, expectativas e dúvidas, construídas, desconstruídas e reconstruídas até então.

\section{CONCLUIR É (IM)PRECISO, NARRAR É (IM)PRECISO TAMBÉM....}

O corpus analisado nesse eixo temático corroborou o referencial teórico adotado acerca das potencialidades formativas das narrativas autobiográficas orais 
e escritas, fomentando novas formas de pensar, sentir e agir dos colaboradores da pesquisa. Os diálogos autobiográficos tornaram-se formativos quando os professores assumiram o papel de colaboradores de sua própria formação conscientizando-se não apenas da necessidade de se autoavaliarem, mas, sobretudo, da necessidade de se desenvolverem enquanto pessoa e profissional. Os resultados mostram que aceitando o desafio de escrever e compartilhar sua história reconheceram seus saberes e assumiram o compromisso com a própria formação.

As narrativas autobiográficas configuraram-se, portanto, como estratégias formativo-investigativas poderosas, não apenas por oportunizarem aos colaboradores da pesquisa a (re)significação e reconfiguração dos espaços, dos tempos e das experiências vivenciadas, mas também por possibilitar-lhes reconhecerem-se como parte integrante e basilar de uma história que não é apenas sua, mas de toda a sociedade.

Em síntese, as narrativas revelam conhecimentos implícitos e próprios do professor; são produzidas em cenários significativos, no caso específico dessa pesquisa, a universidade; corroboram a tradição humana de contar histórias, visto que a narrativa começa com a história da humanidade; permitem que o professor compartilhe suas experiências e aprendizagens consigo e com seus pares; e, por fim, essa estratégia para a produção de dados propicia condições para que se estabeleçam mudanças tanto no campo pessoal quanto profissional do docente em razão de sua dimensão formativa e investigativa.

\section{REFERÊNCIAS}

ABRAHÃO, M. H. M. B. Pesquisa (auto)biográfica: tempo, memória e narrativas. In: ABRAHÃO, M. H. M. B. (Org.). A aventura (auto)biográfica: teoria e empiria. Porto Alegre: Edipucrs, 2004. p. 201-224.

BENJAMIN, W. Magia e técnica, arte e política: ensaios sobre literatura e história da cultura. Tradução de Sérgio Paulo Rouanet. 7. ed. São Paulo: Brasiliense, 1994.

BOLÍVAR, A. Profissão professor: o itinerário profissional e a construção da escola. Bauru: Edusc, 2002.

CHENÉ, A. A narrativa de formação e a formação de formadores. In: NÓVOA, A.; FINGER (Org.). O método (auto)biográfico e a formação. Lisboa: Ministério da Saúde, 1988. p. 87-97.

CUNHA, M T. S. "Por hoje é só...”: cartas entre amigas. In: BASTOS, M. H. C.; CUNHA, M. T. S.; MIGNOT, A. C. V. (Org.). Destinos das letras: história, educação e escrita epistolar. Passo Fundo: UPF, 2002. p. 181- 204. 
CUNHA, R. C. da. Narrativas autobiográficas de professores iniciantes no Ensino Superior: trajetórias formativas de docentes do curso de Letras-Inglês. 2014. 304 f. Tese (Doutorado em Educação)-Universidade Federal de São Carlos, São Carlos, 2014.

CUNHA, M T. S. "Por hoje é só...” cartas entre amigas. In: BASTOS, M. H. C.; CUNHA, M. T. S.; MIGNOT, A. C. V. (Org.). Destinos das letras: história, educação e escrita epistolar. Passo Fundo: Edupf, 2002. p. 181- 204.

DELORY-MOMBERGER, C. Biografia, corpo, espaço. In: PASSEGGI, M. da C. (Org.). Tendências da pesquisa (auto)biográfica. Natal: Edufrn; São Paulo: Paulus, 2008. p. 29-53.

DOMINICÉ, P. Biografização e mundialização: dois desafios contraditórios e complementares. In: PASSEGGI, M. da C.; SOUZA, E. C. de. (Org.). (Auto)biografia: formação, territórios e saberes Natal, RN: Edufrn; São Paulo: Paulus, 2008.

FORMOSINHO, J.; OLIVEIRA-FORMOSINHO, J. Formação, desempenho e avaliação de professores. Mangualde: Edições Pedagogo, 2009.

FREIRE, P. Pedagogia da autonomia: saberes necessários à prática educativa. São Paulo: Paz e Terra, 1996.

FREITAS, D. de; GALVÃO, C. o uso de narrativas autobiográficas para o desenvolvimento profissional de professores. Ciências \& Cognição, v. 12, p. 219-233, 2007.

GALVÃO, C. Narrativas em Educação. Ciência \& Educação, v. 11, n. 2, p. 327 $345,2005$.

GALVÃO, W. N.; GOTLIB, N. B. Prezado, senhor, prezada senhora: estudos sobre cartas. São Paulo: Companhia das Letras, 2000.

GARCIA, C. M. Formação de professores para uma mudança educativa. Porto: Porto, 1999.

GOODSON, I. Professorado e histórias de vida. Tradução Fernando Hernandez. Barcelona: Octaedro, 2005.

GOODSON, I. Dar voz ao professor: as histórias de vida dos professores e o seu desenvolvimento profissional. In: NÓVOA, A. (Org.). Vidas de professores. Portugal: Porto, 2000. p. 69-84.

IBIAPINA, I. M. L. de M. Pesquisa colaborativa: investigação, formação e produção de conhecimentos. Brasília: Liber Livro, 2008.

JOSSO, M. C. Experiência de vida e formação. São Paulo: Cortez, 2004. 
LIMA, E. F. (Org.). Sobrevivências no início da docência. Brasília, DF: Líber Livro, 2006.

MARCUSCHI, L. A O diálogo no contexto da aula expositiva: continuidade, ruptura e integração. In. PRETI, D. (Org.). Diálogos na fala e na escrita. São Paulo: Humanitas, 2004. p. 45.84.

MORAES, R.; GALIAZZI. M. C. Tomando conta do ambiente em que se vive: aprendizagem e apropriação de discursos pela linguagem. Comunicação Oral no II Encontro Internacional da Linguagem, Cultura e Cognição, de 16 a 18 de julho de 2003. Disponível em: <http://www.fc.unesp.br/abrapec/revistas/v3n3a1.pdf>. Acesso em: 18 set. 2013 .

NORÁ, P. Entre memória e História: a problemática dos lugares. Projeto História, São Paulo: PUC, n. 10, p. 7-28, dez. 1993.

NÓVOA, A. Os professores e sua formação. Lisboa: Dom Quixote, 1992.

OLIVEIRA, V. F. de. (Org.). A formação de professores revisita os repertórios guardados na memória. In: OLIVEIRA, V. F. de. (Org.). Imagens de professor: significações do trabalho docente. Ijuí: Unijuí, 2000. p. 11- 34.

PASSEGGI, M. da C. (Org.). Tendências da pesquisa (auto)biográfica. Natal: EDUFRN; São Paulo: Paulus, 2008.

PINEAU, G. As histórias de vida em formação: gênese de uma corrente de pesquisa-ação-formação existencial. Educação e pesquisa, São Paulo, v. 32, n. 2, p. 329343, maio/ago. 2006.

PRADO, G. do V. T.; FERREIRA, C. R.; FERNANDES, C. H. Narrativa pedagógica e memoriais de formação: escrita dos profissionais da educação? Revista Teias, v. 12, n. 26, p. 143-153, set./dez. 2011.

PRADO, G. V. T.; SOLIGO, R. Memorial de formação: quando as memórias narram a história da formação... In: PRADO, G. V. T.; SOLIGO, R. (Org.). Porque escrever é fazer história. Campinas: Alínea, 2007. p. 45-60.

REIS, P. R. As narrativas na formação de professores e na investigação em educação. Nuances: Estudos sobre Educação, v.15, n. 16, p. 17-34, 2008.

SILVA, J. Q. G. Um estudo sobre o gênero carta pessoal: das práticas comunicativas aos indícios de interatividade na escrita dos textos. 2002. 209 f. Tese (Doutorado em Letras)-Universidade Federal de Minas Gerais, 2002. 
SOARES, M. B. Metamemórias-memórias: travessia de uma educadora. 2. ed. São Paulo: Cortez, 2001.

SOUTO MAIOR, A. C. O gênero carta: variedade, uso e estrutura. Ao Pé da Letra, v. 3, n.2, p. 1-13, 2001 .

SOUZA, E. C. de. Histórias de vida, escritas de si e abordagem experiencial. In: SOUZA, E. C. de; MIGNOT, A. C. V. (Org.). Histórias de vida e formação de professores. Rio de Janeiro: Quartet, FAPERJ, 2008. p. 65-88.

SOUZA, E. C. de. O conhecimento de si, as narrativas de formação e o estágio: reflexões teórico-metodológicas sobre uma abordagem experiencial de formação inicial de professores. In: SOUZA, E. C. de. (Org.). A aventura (auto) biográfica: teoria e empiria. Porto Alegre: Edpucrs, 2004. p. 385-386.

SOUZA, E. C. de. Pesquisa narrativa e escrita (auto) biográfica: interfaces metodológicas e formativas. In: SOUZA, E. C. de; ABRAHÃO, M. H. B. Tempos, narrativas e ficções: a invenção de si. Porto Alegre: Edpucrs, 2006. p.135-147.

SUÁREZ, D. A documentação narrativa de experiências pedagógicas como estratégia de pesquisa-ação-formação de docentes. In: PASSEGGI, M. da C.; BARBOSA, T. M. N. Narrativas de formação e saberes biográficos. Natal: Edufrn; São Paulo: Paulus, 2008. p. 101- 149.

ZABALZA, M. A. O ensino universitário: seu cenário e seus protagonistas. Porto Alegre: Artmed, 2004.

ZEICHNER, K. M. Educating reflective teachers for learner-centered education: possibilities and contradictions. In: GIMENEZ, T. Ensinando e aprendendo inglês na universidade: formação de professores em tempos de mudança. Londrina: Abrapui, 2003. p. 3-19.

ZEICHNER, K. M. Para além da divisão entre professor pesquisador e pesquisador acadêmico. In: GERALDI, C. M. G. et al. Cartografias do trabalho docente: professor(a)-pesquisador(a). Campinas: Mercado de Letras, 2000. p. 207-236.

ZEICHNER, K. M. Uma análise crítica sobre a "reflexão" como conceito estruturante na formação docente. Educação \& Sociedade, Campinas, v. 29, n. 103, p. 535-554, maio/ago. 2008.

Artigo Recebido em: 14 de setembro de 2015

Aceito em: 17 de dezembro de 2015

Endereço para correspondência: Rodovia Washington Luís, s/n, Jardim Guanabara, 13565-905, São Carlos, São Paulo, Brasil; rosa@ufscar.br 
